\title{
Investigation of the Gas-Phase Structure of Electrosprayed Proteins Using Ion-Molecule Reactions
}

\author{
Rachel R. Ogorzalek Loo* and Richard D. Smith \\ Chemical Methods and Separations Group, Chemical Sciences Department, Pacific Northwest Laboratory, \\ Richland, Washington, USA
}

Proton transfer reactions of ammonia, dimethylamine, diethylamine, and trimethylamine with multiply protonated proteins generated by electrospray ionization (ESI) were examined to probe the relationship between solution and gas-phase protein structure and the relationship with ion-molecule reactivity. The ion-molecule reactions were carried out in an atmospheric pressure capillary inlet/reactor based upon an ESI interface to a quadrupole mass spectrometer. Two types of systems were explored: (1) proteins possessing cysteinecysteine disulfide bonds and the analogous disulfide-reduced proteins, and (2) proteins sprayed from solution compositions where the protein has different conformations. While the cysteine-cysteine disulfide-bound proteins were more reactive than equally charged disulfide-reduced proteins under these conditions, no significant reactivity differences were noted for ions arising from different solution conformations. The effect of inlet/reactor temperature on charge distributions with and without amine reagent was also explored, demonstrating that thermal denaturation of proteins can occur in heated capillary inlets. The results are discussed in the context of recent results indicating the persistence of at least some higher order protein structure in the gas phase. (J Am Soc Mass Spectrom 1994, 5, 207-220)

$\mathrm{T}$ he introduction of electrospray ionization (ESI) to mass spectrometry [1] has provided exceptional opportunities for studying macromolecules in the gas phase [2-4]. These new capabilities also bring new questions, particularly with regard to gas-phase ion structure and its relationship to structure in solution. Measurement methods reflecting primary structure of biopolymers (e.g., the sequence for proteins) have been rapidly developed, with molecular weight determinations, peptide mapping, and tandem mass spectrometry (MS/MS) finding immediate applications in structure confirmation [5]. Questions regarding preservation of noncovalent associations in the gas phase, while more difficult to answer than those regarding primary structure, are proving to be experimentally tractable because they also rely upon molecular weight measurements [6-17]. Examining the higher order gas-phase structure of proteins by mass spectrometry is particularly difficult [18-20] because in most cases the relevant structural differences do not lead to differences in molecular weight, although in some cases arguments can be posed based on the

Address reprint requests to Richard D. Smith, Chemical Methods and Separations Group, Chemical Sciences Department, Pacific Northwest Laboratory, Richland, WA 99352.

*Current address: Protein and Carbohydrate Structure Facility, 2552 MSRBII, University of Michigan, Ann Arbor, MT 48109. observation of buried solvent molecules in protein crystals and their presence or absence in ESI mass spectra [9]. The strikingly different ESI charge-state distributions observed for different solution conformers of many proteins [10, ?0-27] demonstrate the utility of ESI as a probe of solution conformation, but do not inform as to whether the resulting gas-phase proteins differ in any way other than in charge. Some of the questions which arise include: (1) whether the differences in ESI mass spectra of native and denatured protein solutions reflect only differences arising from different structure or charging in solution (i.e., net charge and charge location), (2) whether a structural examination of equally charged gas-phase ions prepared from ESI of native and denatured solutions would show them to be the same (e.g., would the same residues be charged and would the three-dimensional structure be the same), and (3) whether structurally different conformers isomerize to the same gas-phase species after ESI.

One approach to probing the gas-phase structure of proteins is to examine how structure affects reactivity; several previous studies that investigated collisional dissociation and ion-molecule reaclions reflect this approach. Collisional dissociation studies have established differences in fragmentation between "native" and disulfide-reduced proteins attributed to the additional bonds constraining the covalently disulfide- 
bridged proteins [28-30]; however, these studies are not informative regarding preservation of the much weaker noncovalent associations that can distinguish different protein conformations. Differences were also observed in the collisional dissociation of two ubiquitin conformers [24]. The product ion spectrum of the $(\mathrm{M}+7 \mathrm{H})^{7+}$ charge state from one conformer was compared to the product ion spectrum of the $(\mathrm{M}+$ $11 \mathrm{H})^{11+}$ charge state from the other conformer at constant laboratory-frame collision energies. Large differences were observed in the dissociation spectra of the different charge states. However, the comparison of MS/MS data from the same charge states produced from different solvent conditions (known to support different solution structures) yielded only minor differences. Feng and Konishi [31a] have argued that collisional attenuation studies involving myoglobin and papain show a discontinuity in the intensity pattern where ions from two conformational states have a similar number of charges, suggesting that gas-phase conformation rather than the velocity difference during collisions was the major cause for the dramatic collisional attenuation differences. Covey and Douglas [31b] have measured smaller collision cross sections for cytochrome $c$ ions from aqueous solutions versus solutions electrosprayed from higher organic content solutions, suggesting possible differences in gas-phase structure. A limitation of all low energy collisional dissociation studies conducted to date is that protein ions are collisionally activated under multiple collision conditions on the microsecond time scale, and it is feasible that isomerization to similar structures can occur prior to dissociation.

An alternative approach to gas-phase structural studies (that can avoid collisional heating and isomerization) involves the use of low energy ion-molecule reactions. Ion-molecule reactions of ESI-generated ions, originally demonstrated by McLuckey et al. [32-35a] have been extended to gas-phase conformation studies by three groups [18-20,36-39]. Differences in proton transfer reactivity were established between disulfide-intact and disulfide-reduced proteins in a capillary inlet-reactor [18]. Subsequently, reactivity differences to hydrogen/deuterium $(\mathrm{H} / \mathrm{D})$ exchange have also been noted for disulfide-intact and disulfide-reduced proteins for reactions carried out in a capillary irlet/reactor [19] and in a Fourier transform mass spectrometer (FTMS) [20]. The FTMS H/D exchange results also provided dramatic evidence for retention of conformational differences in the gas phase for nondisulfide-linked proteins. Surprisingly, the inlet/ reactor $\mathrm{H} / \mathrm{D}$ exchange studies [39] failed to uncover reactivity differences for nondisulfide-linked proteins.

In this article we extend our previous ion-molecule reaction studies [18] and include additional reagents and proteins. A major emphasis of the present report is on the reactivity of protein conformers not linked by disulfide bonds, and on investigating conditions for transport through the capillary inlet that are least

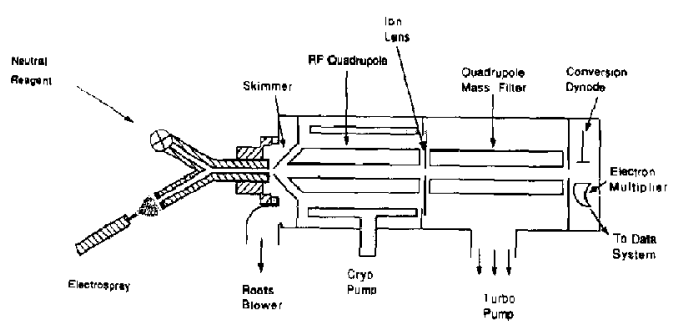

Figure 1. Diagram of the ESI mass spectrometer interface incorporating the Y-shaped capillary reactor inlet. (Not drawn to scale.)

likely to perturb gas-phase structure. We discuss these results in the light of the array of apparently conflicting results regarding preservation of higher order structure in the gas phase, and suggest a possible explanation.

\section{Experimental}

The ESI source and the prototype mass spectrometer employed in these studies have been described previously $[40,41]$. A stainless-steel capillary interface/flow reactor (inlet) (Figure 1) was substituted for the nozzle inlet design used in earlier work [18, 42, 43]. The Y-shaped flow reactor merges two streams of ions [42, 43] or a stream of ions entrained in a gas flow and a stream of neutral reactant gas $[16,18]$ to interact at near atmospheric pressure. Inlet/reactors were constructed from $0.16 \mathrm{~cm}$ o.d., $0.10 \mathrm{~cm}$ i.d. stainless-steel tubing soldered to a stainless steel post into which had been drilled a $0.1 \mathrm{~cm}$ dia. Y-shaped channel. A variation upon this reactor, fabricated from commercially available fittings, has been previously employed to study reactions between multiply charged proteins and $\mathrm{H}_{2} \mathrm{O}$ or $\mathrm{D}_{2} \mathrm{O}[16,19,36,39]$.

Desolvation of electrosprayed droplets was accomplished by electrically heating the capillary $[44,45]$ with currents from $0-20$ amps applied across one arm of the inlet. The neutral reagent inlet arm was not heated, and very little heat transfer occurred between heated and unheated portions of the metal reactor. Capillary temperatures were indicated by a chromel alumel thermocouple attached to the outer wall of the inlet; gas temperatures are expected to be lower than the inlet wall temperature. Because heat transfer is much poorer in larger inner diameter capillaries, higher wall temperature must be employed for a $0.1 \mathrm{~cm}$ capillary to achieve the same gas temperatures as for a $0.05 \mathrm{~cm}$ capillary $[16,19,36,39]$. Additional desolvation was achieved by collisional dissociation in the capillary outlet-skimmer (OS) region at capillary biases from $0-500 \mathrm{~V}$ relative to the grounded skimmer. Countercurrent gas flow in the atmospheric pressure electrospray region was not employed in these studies.

An ESI source was positioned $0.5-1 \mathrm{~cm}$ from one inlet, while the second inlet delivered the neutral 
reagent. Measurements from a thermocouple gauge off-axis from the molecular beam indicated that the pressure in the first differentially pumped region was 1 torr with the reagent inlet sealed, and increased by a few tenths of a torr with addition of the maximum amount of amine reagent used in these studies. Delivery of ammonia, dimethylamine (DMA), and trimethylamine (TMA), gases at room temperature with proton affinities of $205.0,220.5$, and $224.3 \mathrm{kcal} / \mathrm{mol}$, respectively [46], was controlled by a pressure regulator and needle valve (open inner diameter $=0.079 \mathrm{~cm}$ ). The reagent pressure upstream of the needle valve was maintained at $1 \mathrm{~atm}$. Based on the flow characteristics of the needle valve and reactor assembly, the ammonia, DMA, and TMA flows ranged from approximately 0 to $1 \times 10^{-2} \mathrm{~g} / \mathrm{sec}, 0$ to $2 \times 10^{-2} \mathrm{~g} / \mathrm{sec}$, and 0 to $3 \times 10^{-2} \mathrm{~g} / \mathrm{sec}$, respectively, depending on the needle valve setting employed. Flow rates at selected needle valve settings on the capillary inlet/flow reactor were determined through evacuation rate measurements with air-filled, calibrated sampling bags. Experimentally determined air flow rates were corrected for the molecular weight difference between the amine reagent and air. Flow measurements were performed at capillary inlet/reactor temperatures of $100{ }^{\circ} \mathrm{C}$ and $150^{\circ} \mathrm{C}$. This approach to delivery of the amine reagent allowed the reagent to be mixed with the gas flow entraining the protein ions downstream in the inlet/reactor. In particular, the solution at the tip of the ESI needle was not exposed to amine, preventing its $\mathrm{pH}$ from being altered during the study.

Liquid and solid reagents with vapor pressures lowner than the pressure in the flow reactor's interaction region were introduced as mixtures with room air or with pressurized gases or alternatively heated to increase their vapor pressure. Should the pressure behind the needle valve not exceed the pressure in the interaction region, diffusion would be the only means of transporting reagent to the mixing region of the inlet/flow reactor, making a determination of the amount of reactant employed more difficult. Diethylamine (DEA), proton affinity $225.1 \mathrm{kcal} / \mathrm{mol}$ [46], boiling point $56.3^{\circ} \mathrm{C}$ at $1 \mathrm{~atm}$ was introduced as a saturated, atmospheric pressure mixture of air and amine vapor by employing a bubbler assembly upstream of the shutoff and needle valves. Because we suspected that the mixture was not saturated with amine at the highest flow rates studied, we limit our discussion of DEA reactions to data acquired at flow rates from 0 to $3 \times 10^{-4} \mathrm{~g} / \mathrm{sec}$, where we believe the mass flow estimates should be reliable. (At high flow rate conditions, saturation was not achieved, which was evident from the observation that shifts in charge-state distributions decreased with time after changing from a lower flow rate to a higher flow rate.) For each needle valve setting, charge shifts observed in the ESI mass spectra were monitored over time to ensure that the amine partial pressure had attained a stable value.

The mass spectrometer's resolution was adjusted to be constant over the $m / z 600-2000$ range to reduce the decrease in sensitivity at higher mass-to-charge ratios generally experienced with quadrupole mass spectrometers under normal tuning conditions (i.e., where resolution increases linearly with $\mathrm{m} / \mathrm{z}$ ). Thus, peak intensities are expected to better represent actual abundances than would typically be the case; however, differences with charge state in the optimum capillary-skimmer bias and detector response, as well as uncertainties in the mass spectrometer's transmission characteristics, preclude an unambiguous comparison based upon measured abundances. Similarly, at low $m / z$, protonated amines were observed as reaction products but were not quantitated or directly compared to the amount of protein reacted because of the widely differing optimal capillary-skimmer potentials for kilodalton proteins and for molecules of $m / z<200$.

The ESI source employed a sheath solvent flow, as described previously $[41,47,48]$, but these studies required compatibility of the selected sheath solvent with the solution phase higher order structure under study. For example, methanol denatures cytochrome $c$ and would not be an ideal sheath solvent for studies investigating folded conformations of cytochrome $c$ in solution. Deionized water was employed for studies with protein solutions incompatible with organic sheath solvents. Studies seeking an unfolded solution conformation used methanol or acetonitrile as the sheath solvent. $\mathrm{SF}_{6}$, employed as the sheath gas, was particularly helpful in stabilizing aqueous electrosprays [49].

With the exception of bovine proinsulin (Novo BioLabs, Danbury, CT), all biochemical samples and DEA were obtained from Sigma Chemical Co. (St. Louis, $\mathrm{MO}$ ) and were used without further purification. DMA and TMA were obtained from Aldrich Chemical $\mathrm{Co}$. (Milwaukee, WI), while ammonia was obtained from Matheson (East Rutherford, NJ). Reduction of disulfide bonds in bovine alpha lactalbumin, bovine proinsulin, chicken egg lysozyme, and bovine albumin was carried out overnight at $37^{\circ} \mathrm{C}$ and for 1 minute at $80^{\circ} \mathrm{C}$ in distilled water with 1,4-dithiothreitol (DTT) [50]. The protein/DTT solutions were acidified and studied by ESI-MS immediately following reduction to minimize reformation of disulfide bonds.

\section{Results and Discussion}

\section{Considerations in Atmospheric Pressure Ion-Molecule Studies}

Our previous study [18] discussed several important issues and assumptions regarding reaction studies with multiply charged ions in the atmospheric pressure/vacuum interface region; a few of those points are highlighted here. First of all, our interface reactions rely upon much higher neutral reagent gas flows than do the previous quadrupole ion trap mass spectrometer (ITMS) [32-35a] and FTMS [20] studies of reactions of multiply charged ions. These higher gas flows ensure 
that the reactions proceed sufficiently during the approximately millisecond ion transit time through the capillary reactor so as to result in significant contributions from proton transfer reactions having smaller rate constants than those studied in the quadrupole ion trap [33]. The higher pressures in the inlet reactors also mean that the measurements can reflect contributions due to termolecular as well as bimolecular reactions. Thermal reaction conditions dictated by the capillary temperature should apply to the inlet/reactor at the relevant temperatures, as opposed to the uncertain temperatures at the low pressures of the ion trap studies. Temperature dependencies of reaction rates can also be explored by varying the capillary reactor temperature. Additional interactions are possible in the capillary reactor because solvent and air are generally also present. In particular, the influence of solvation on proton transfer reactions may be explored with the inlet/reactor approach, or solvent contributions can be reduced using a countercurrent gas flow, which facilitates solvent evaporation of the electrosprayed droplets and prevents most solvent vapor from entering the capillary reactor. The unique environment of the flow reactor is therefore expected to provide an interesting comparison to measurements performed in ITMS and FTMS instruments.

Under the conditions used in this study, reactions occur after droplet evaporation and ion desorption/ formation are expected to be complete, although the extent of macro-ion solvation observed will likely depend upon the capillary temperature and whether countercurrent gas is employed. We believe that the protein ions are sufficiently desolvated in the capillary inlet region prior to contacting the amine reagent. Nevertheless, the potential problem of insufficient solvent evaporation might lead to an increase in the droplet $\mathrm{pH}$, potentially altering the protein conformation in solution prior to ion desorption. Although unlikely on the millisecond reaction time scale, such behavior could prevent us from observing differences in reactivity for ions sprayed from different solution compositions. We believe that such a problem would likely be diagnosed by the large difference in charge state it should cause. In particular, solution-phase conformational changes would not be expected to show the smooth decrease in charge state as more and more reagent was added. Rather, they should show a large jump in charge state when the solution $\mathrm{pH}$ was elevated sufficiently to cause the conformational change. Observations of a bimodal charge-state distribution might occur for droplet reactions. No such behavior was observed in our experiments, suggesting that desolvation was largely complete.

The supersonic expansion which follows the interaction region also can give rise to potential problems in interpretation, particularly with regard to the competition between proton transfer and clustering. These difficulties in interpretation are avoided in the present study, however, because reactivities are compared under identical instrumental conditions and we are only looking for differences in reactivity.

Rate measurements with the inlet/reactor are more complicated than with the ITMS and FTMS instruments for several reasons. Initially, pressure is not constant through the entire capillary inlet/reactor and depends on the reactor's dimensions. Consequently, we report reagent flow rates rather than pressures as the relevant quantities reflecting the reactivities of particular gases and charge states. Isolation of a single charge state in the ITMS and FTMS instruments enables reaction rates to be measured directly, while the inlet/reactor shows only the combined effect of reaction of all of the charge states. There are certain regimes, however, where examination of the shifts in the charge-state distributions may still be informative. One such regime is under conditions inducing large charge-state shifts, where the decrease in reaction rate with decreasing charge state is dramatic.

The fundamental assumptions we make in our interpretation are that (1) reaction rates are faster for higher charge states than for lower charge states and (2) that the $[\mathrm{M}+\mathrm{nH}]^{\mathrm{n}+}$ charge state reacts to form an $[M+(n-1) H]^{(n-1)+}$ charge state with reactivity equal to that of the $[M+(n-1) H]^{(n-1)+}$ species formed initially by ESI of that conformer. That assumption (1) be valid is desirable so that the highest charge states (i.e., those initially produced from ESI of the unfolded protein) react with the amine quickly enough to eliminate any differences arising purely from the chargestate distributions yielded by electrospray of the conformers. Higher reactivity is expected due to the greater Coulombic contribution to barrier lowering for such proton transfer processes. Direct support for assumption (1) is provided by ITMS rate measurements [32, 33]. We have taken care to conduct our studies in a high reactant-flow regime where assumption (1) is most likely to be justified. All proteins that we have examined show decreasing reactivity with decreasing charge state, although we have observed at very low amine flow rates that several of the highest charge states from ESI of the denatured proteins disappear nearly simultaneously. The reaction rates for these higher charge states are very fast, and limitations in our ability to control reactant flow rates do not allow us to observe differences in their rates of disappearance.

The validity of assumption (2) is also somewhat important to our interpretation. If the ions produced by the proton transfer reactions are not as reactive as equally charged ions produced directly by EST (e.g., if the sites charged by ESI reflect energetically the most stable sites in solution, but not in the gas phase), interpretation of the charge-distribution shifts would be more difficult. Should assumption (2) be invalid, bimodal charge-state distributions may be observed after proton transfer reaction, at least under certain experimental conditions, reflecting the different reaction rates for equally charged ions. Bimodal charge-state distributions were not observed at any of the reagent 
flows employed in this study. Furthermore, as individual charge states were monitored while the DEA flow rate was varied, no evidence of behavior that would invalidate either assumptions (1) or (2) was observed. For example, a peak for a specific charge-state ion was not observed to decrease in abundance at medium reagent flows and subsequently increase at higher flows. Direct measurement of ion-molecule reaction rates in FTMS and ITMS instruments may provide further tests of these assumptions.

\section{Reactions of Disulfide-Bound Proteins}

As a starting point, we examined systems for which it has been shown that structural differences persist in the gas phase: specifically, the comparison of cysteine-cysteine disulfide-reduced and disulfide-intact proteins [28-30, 51, 52]. Earlier studies reacted DEA with bovine pancreatic trypsin inhibitor $\left(\mathrm{M}_{\mathrm{r}} 6512\right.$, three disulfide linkages), hen egg-white lysozyme $\left(M_{r} 14,306\right.$, four disulfide linkages), and bovine albumin ( $\mathrm{M}_{\mathrm{r}}$ $66,430,17$ disulfide linkages) and showed dramatic differences in charge-state distributions between disulfide-intact and disulfide-reduced proteins to which equal amounts of DEA had been added [18]. There was no evidence of the highest charge state observed after reaction of the disulfide-intact species ever equaling or exceeding that for the disulfide-reduced species after reaction. Based on those results, it was argued that increased electrostatic repulsion caused a disulfide-intact protein to be more reactive to proton transfer than the equally charged disulfide-reduced protein.

In extending those studies to other amine reagents, we observed similar behavior in the reactions of DMA with bovine albumin and hen lysozyme. Once again, the highest charge state observed after reaction of the disulfide-intact protein was always smaller than that for the reduced protein following reaction.

Millisecond time scale gas-phase $H / D$ exchange experiments using a similar experimental arrangement have shown that disulfide-bound alpha lactalbumin $\left(M_{r} 14,175\right)$ and proinsulin exchange deuterium for protium more rapidly than do the reduced proteins [36], in contrast to solution-phase studies [23]. The gas-phase $H / D$ exchange behavior may be influenced by electrostatic contributions that would also be expected for proton transfer reactions with amines. Figures 2 and 3 illustrate the results for DMA reactions with alpha lactalbumin. The mass spectra were obtained at a capillary-skimmer bias of $+350 \mathrm{~V}$ and a capillary inlet temperature of $150^{\circ} \mathrm{C}$. After addition of $2 \times 10^{-5} \mathrm{~g} / \mathrm{sec}$ of DMA to disulfide-bound alpha lactalbumin (see Figure 2b), only the $(\mathrm{M}+8 \mathrm{H})^{8+}$ charge state was observed in the $m / z 2000$ range of our mass spectrometer, and it is ciear from the $8+$ charge state's low relative abundance that most of the ions have shifted to even lower charge states. Indeed, a DMA flow of roughly $1 / 10$ that is illustrated in Figure $2 b$ is sufficient to shift the charge distribution to the

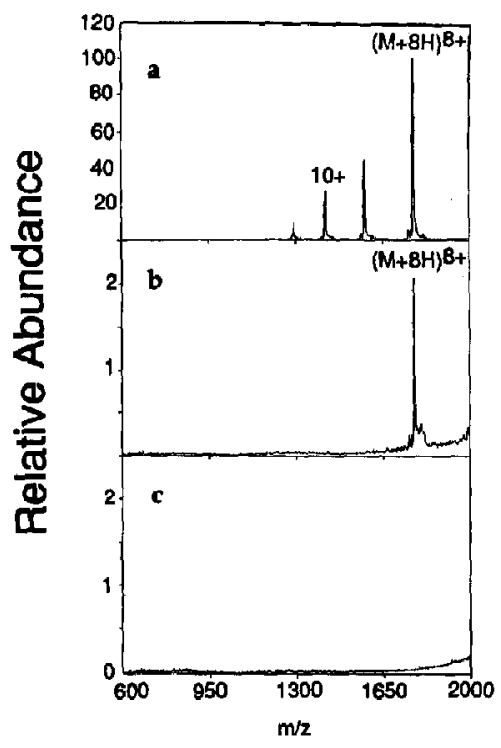

Figure 2. (a) ESI mass spectrum of disulfide-intact alpha lactalbumin in $5 \%$ acetic acid/water with a methanol sheath liquid (capillary-skimmer bias: $+350 \mathrm{~V}$; capillary temperature: $150^{\circ} \mathrm{C}$ ). (b) As above, but with the addition of $2 \times 10^{-5} \mathrm{~g} / \mathrm{sec}$ DMA. (c) As above, but with the addition of $1 \times 10^{-3} \mathrm{~g} / \mathrm{sec}$ DMA.

$8+$ charge state and lower. As shown in Figure $2 c$, all the protein ions have shifted to charge states $<8+$, beyond the $m / z$ range of our mass spectrometer, at the higher DMA flow. In striking contrast to this

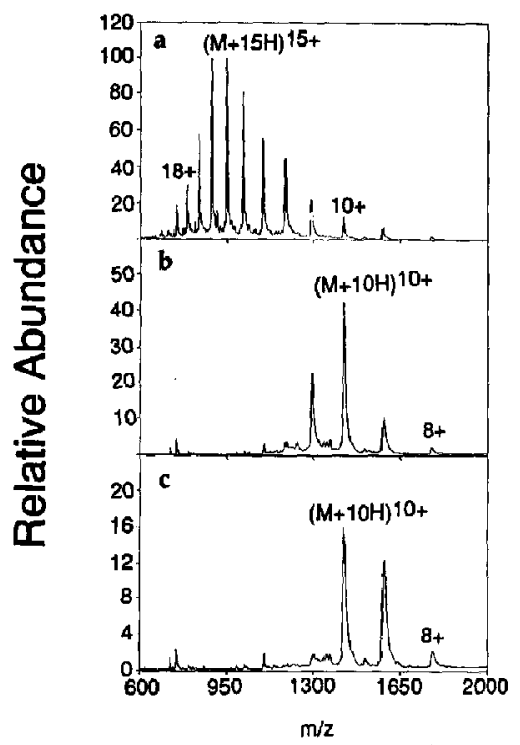

Figure 3. (a) ESI mass spectrum of reduced alpha lactalbumin in $5 \%$ acetic acid/water with a methanol sheath flow (capillaryskimmer bias: $+350 \mathrm{~V}$; capillary temperature: $150{ }^{\circ} \mathrm{C}$ ). (b) As above, but with the addition of $2 \times 10^{-5} \mathrm{~g} / \mathrm{sec}$ DMA. (c) As above, but with the addition of $1 \times 10^{-3} \mathrm{~g} / \mathrm{sec}$ DMA. 
behavior, for the disulfide-reduced protein the $(\mathrm{M}+$ $9 \mathrm{H})^{9+}$ is still observed with 50 times more reagent than employed in Figure 2b, as shown in Figure 3c.

Similar results are observed in the comparison of other disulfide-intact and disulfide-reduced proteins. As an example, results for proton transfer from bovine proinsulin to DMA are illustrated in Figures 4 and 5, employing a capillary-skimmer bias of $+350 \mathrm{~V}$ and capillary temperature of $150^{\circ} \mathrm{C}$. As shown, proinsulin with its three disulfide bonds intact was also observed to be more reactive to proton transfer than the reduced protein over the range of conditions examined. These results are consistent with the previous $H / D$ exchange studies and show that structural differences will be manifested by substantial differences in proton transfer reactivity for highly charged proteins in the gas phase.

\section{Reactions of Proteins with Different Solution Conformations-Ubiquitin}

Our results showing differences in reactivity between disulfide-intact and disulfide-reduced proteins provided a foundation for determining whether corresponding differences in reactivity could be observed for ions produced from different solution conformations. The solution conformation experiments are a "fishing expedition" of sorts because it is not clear that proton transfer is the best method to probe subtle conformational effects, nor is it clear whether any or all conformational differences will be retained under all ESI interface conditions. Certainly the $\mathrm{H} / \mathrm{D}$

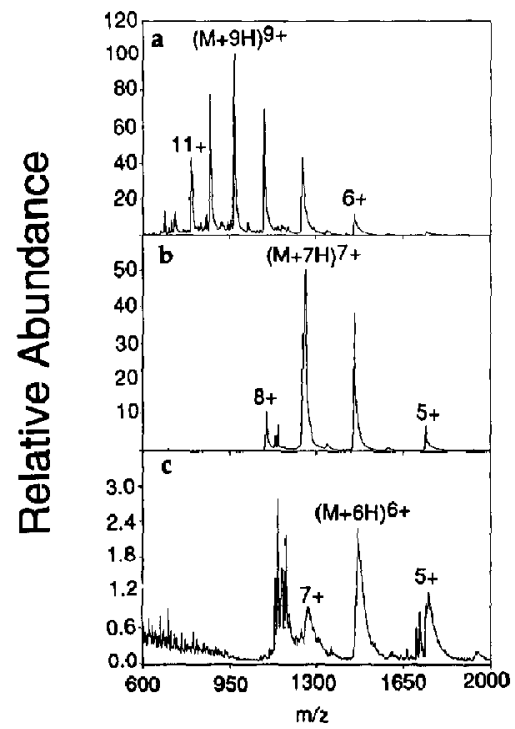

Figure 4. (a) ESI mass spectrum of reduced bovine proinsulin in $5 \%$ acetic acid/water with a methanol sheath flow (capillaryskimmer bias: $+350 \mathrm{~V}$; capillary temperature: $150^{\circ} \mathrm{C}$ ). (b) As above, but with the addition of $2 \times 10^{-5} \mathrm{~g} / \mathrm{sec}$ DMA. (c) As above, but with the addition of $8 \times 10^{-4} \mathrm{~g} / \mathrm{sec}$ DMA.

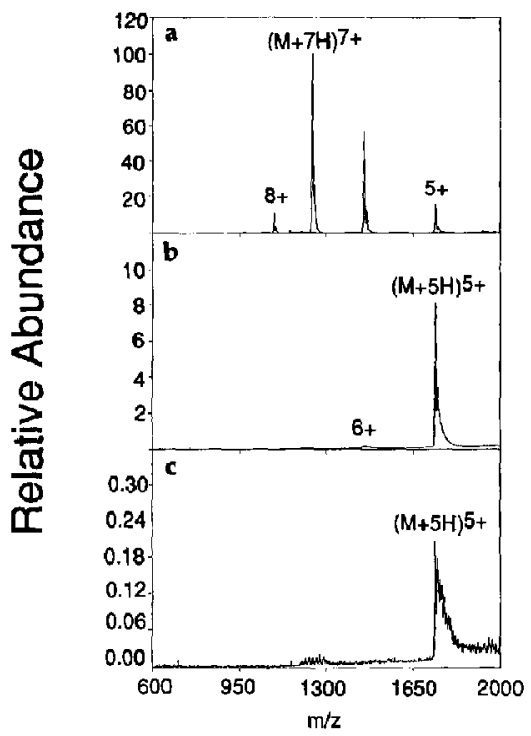

Figure 5. (a) ESI mass spectrum of bovine proinsulin in $5 \%$ aretic acid/water with a methanol sheath flow (capillary-skimmer bias: $+350 \mathrm{~V}$; capillary temperature: $150{ }^{\circ} \mathrm{C}$ ). (b) As above, but with the addition of $2 \times 10^{-5} \mathrm{~g} / \mathrm{sec}$ DMA. (c) As above, but with the addition of $8 \times 10^{-4} \mathrm{~g} / \mathrm{sec}$ DMA.

exchange results from McLafferty and co-workers [20] present a strong case for preservation of at least some higher order structure in the gas phase. If significant differences in reactivity from ions generated from different solutions are not observed, we cannot conclude that the ions have the same higher order structure, we conclude merely that we cannot see evidence of differences. However, should convincing differences in reactivity be abserved, it can be argued that they arise from the higher order structure. We have examined reactions of myoglobin, ubiquitin, and cytochrome $c$, three proteins well known for their conformational effects on ESI spectra.

The first protein, bovine ubiquitin $\left(M_{r} 8565\right)$, was examined under three solution conditions: (1) a water solution electrosprayed with a water sheath, (2) a $5 \%$ acetic acid $/ \mathrm{H}_{2} \mathrm{O}$ solution electrosprayed with a water sheath, and (3) a $47.5 \%$ acetonitrile $/ 47.5 \% \quad \mathrm{H}_{2} \mathrm{O} / 5 \%$ acetic acid solution electrosprayed with an acetonitrile sheath. A small contribution was also observed in the ubiquitin sample due to an inactive form of the protein, "ubiquitin $t^{\prime \prime}$ [53], missing the two C-terminal glycines $\left(M_{r}\right.$ 8451). Additional peaks reflecting adducted sulfate or phosphate counterions appear under some conditions (e.g., usually at low capillary temperature, low capillary-skimmer bias). Figures 6 and 7 show some of the resulting spectra illustrating reactivities with TMA. Figure fa shows the ESI mass spectrum obtained for the acetonitrile $/ \mathrm{H}_{2} \mathrm{O} /$ acetic acid solution without addition of TMA at a capillary inlet temperature of $150{ }^{\circ} \mathrm{C}$ and $175 \mathrm{~V}$ capillary- 


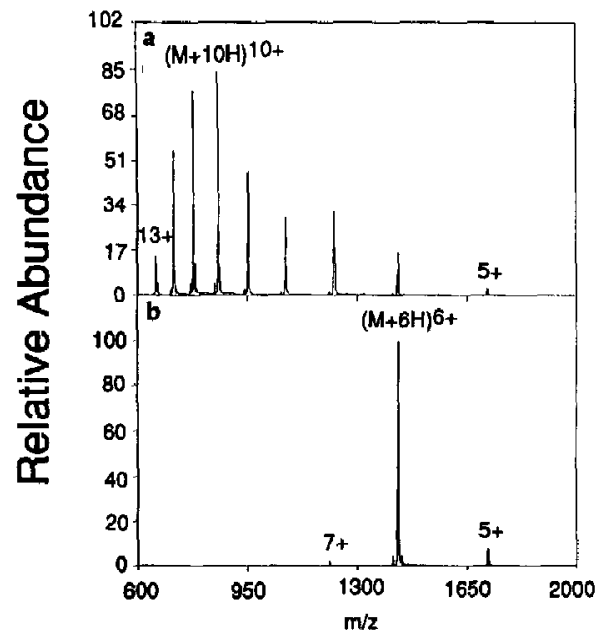

Figure 6. (a) ESI mass spectrum of bovine ubiquitin ( $\left.M_{r} 8565\right)$ in $47.5 \%$ acetonitrile, $47.5 \% \mathrm{H}_{2} \mathrm{O}, 5 \%$ acetic acid with an acetonitrile sheath flow (capillary-skimmer bias: $+175 \mathrm{~V}$; capillary temperature: $150{ }^{\circ} \mathrm{C}$ ). (b) As above, but with the addition of $6 \times$ $10^{-5} \mathrm{~g} / \mathrm{sec}$ TMA.

skimmer bias. Upon addition of $6 \times 10^{-5} \mathrm{~g} / \mathrm{sec}$ TMA, the charge-state distribution shifts to primarily $(M+$ $6 \mathrm{H})^{6+}$ (Figure 6b). Figure 7 compares data obtained under the same conditions, but by electrospraying the protein in water and with a coaxial water sheath. Surprisingly, no significant differences are observed between Figures $6 \mathrm{~b}$ and $7 \mathrm{~b}$ and, in general, for comparisons between the two solutions with TMA additions ranging from $3 \times 10^{-5}$ to $3 \times 10^{-4} \mathrm{~g} / \mathrm{sec}$. (Higher amine flows shifted all of the ubiquitin charge states beyond our mass spectromeler's $m / z$ range.) Similar

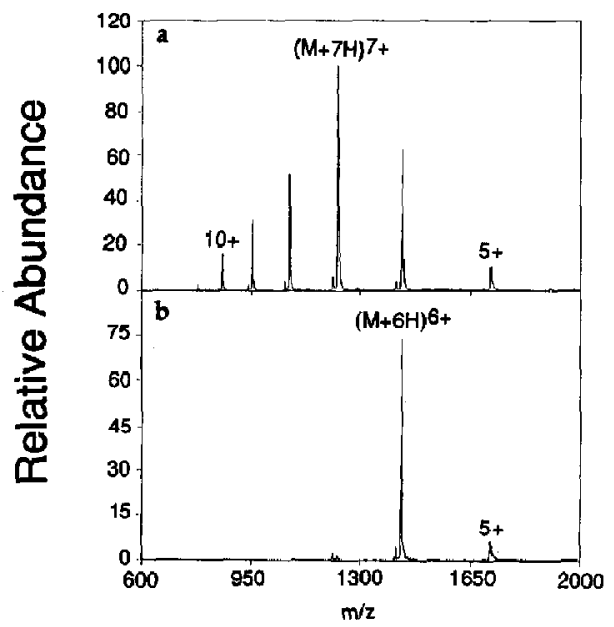

Figure 7. (a) ESI mass spectrum of bovine ubiquitin in $\mathrm{H}_{2} \mathrm{O}$ employing a water sheath flow (capillary-skimmer bias: $+175 \mathrm{~V}$; capillary temperature: $150^{\circ} \mathrm{C}$ ). (b) As above, but with the addition of $6 \times 10^{-5} \mathrm{~g} / \mathrm{sec}$ TMA. behavior was observed for reactions with ions generated by ESI of a solution in $5 \%$ acetic acid $/ \mathrm{H}_{2} \mathrm{O}$ sprayed with a water sheath. Comparisons in reactivity were also made with DEA and DMA; no differences in reactivities were noted for additions over the ranges $3 \times 10^{-5}$ to $3 \times 10^{-4} \mathrm{~g} / \mathrm{sec}(\mathrm{DEA})$ and $2 \times 10^{-5}$ to $3 \times 10^{-4} \mathrm{~g} / \mathrm{sec}$ (DMA) for ions generated from ESI of different solution conformations. A small contribution from ubiquitin dimer, $(2 \mathrm{M}+9 \mathrm{H})^{9+}$, appears in the $\mathrm{H}_{2} \mathrm{O}$ spectrum when water is used as a sheath liquid. Its presence under mild ESI conditions is not unusual $[12,15,16]$ but it is interesting to note that the dimer $9+$ charge state disappears upon addition of $6 \times 10^{-5} \mathrm{~g} / \mathrm{sec}$ of TMA (Figure $7 \mathrm{~b}$ ). Such an observation suggests that either the proton transfer reactions are sufficiently exothermic to dissociate noncovalently bound complexes, or that the noncovalent dimers might be more reactive to proton transfer than monomers with half as many charges. In fact, this observation is not general. Proton transfer experiments with ubiquitin and cytochrome $c$ dimers under slightly different conditions have shown the continued presence of dimer ions with the addition of amine reagents. Such observations may arise from different dimer structures, but clearly more study is required.

\section{Temperature Effects in the Inlet/Reactor Region}

A major concern in the present experiments is that thermal denaturation could occur in the heated inlet during desolvation. Thermal denaturation in solution has been demonstrated to lead to increased charge states being observed in the ESI mass spectra for several systems [22, 26]. However, denaturation occurring after most or all of the solvent has evaporated would not necessarily be expected to lead to increased charging, because the charge state may already be "locked in" and Coulombic considerations should prevent additional charges from being acquired. The lower charge states usually produced from ESI of a "folded" conformation are likely to be as stable or more stable upon unfolding, at least from an electrostatic point of view [54], and so a change in charge-state distribution might or might not accompany a denaturation occurring downstream of the ESI needle. To investigate the possibility of thermal denaturation in the capillary inlet and possible effects on our experiments, we examined ESI charge-state distributions (without addition of amines) as a function of temperature. If the charge distribution was sensitive to temperature, we concluded that denaturation occurring in the microdroplet (or before solvent evaporation was complete) was a possibility and considered these systems to be ones where particular caution was warranted for interpretation of the proton transfer experiments. If we suspect denaturation attributable to the microdroplet environment, it is difficult to exclude the possibility that at lower temperatures denaturation occurs farther downstream in the capillary after more solvent has 
been removed. (We note that an alternate explanation for the observed variability of charge-state distributions with temperature has been offered by Fenn et al. [3b] and discussed by LeBlanc et al. [26]. In that scenario it is suggested that at elevated temperatures the microdroplets shrink to smaller sizes, causing relatively more of the highly charged ions to desorb. If the latter explanation is correct, then sensitivity of chargestate distributions to temperature would not necessarily indicate thermal denaturation.)

It should be restated that for the $0.1 \mathrm{~cm}$ i.d. capillaries of the length used in these studies, the capillary wall temperature in the reaction region may be somewhat greater than the temperature of the bath gas inside the capillary, based on previous studies of ribonuclease S (RNase S) dissociation [11]. Those studies showed that a significant amount of the RNase $S$ complex was observed at capillary temperatures of $110^{\circ} \mathrm{C}$, despite the fact that the complex dissociates into S-protein and S-peptide at solution temperatures exceeding $60^{\circ} \mathrm{C}[10,11]$. While the solution- and gasphase results are not directly comparable due to the differences in time scales and solvent environment, they do suggest the possibility that the bath gas temperature is actually lower than reported.

Charge-state distributions resulting from ESI of bovine ubiquitin in $47.5 \%$ acetonitrile $/ 47.5 \% \mathrm{H}_{2} \mathrm{O} / 5 \%$ acetic acid with an acetonitrile sheath and in $5 \%$ acetic acid $/ \mathrm{H}_{2} \mathrm{O}$ with a water sheath did not change as capillary temperature was varied from $40{ }^{\circ} \mathrm{C}$ to $180^{\circ} \mathrm{C}$. Above $180^{\circ} \mathrm{C}$ significant product ion contributions from thermally induced dissociation were observed $[44,45]$. It is not surprising that the spectrum for ubiquitin in an acidified organic solution did not change with increasing temperature, because the protein is already denatured under those conditions. The ESI mass spectra for ubiquitin in 5\% acetic acid/water sprayed with a water sheath also did not change significantly as the inlet/reactor temperature was elevated, although previously reported studies did show thermal denaturation behavior in solution for similar compositions [22]. We attribute the differences in the two experiments to the thermal stability of ubiquitin; Chait and co-workers [22] have previously shown that heating a pH 2.8 solution to more than $60^{\circ} \mathrm{C}$ was required before significant changes were noted in the spectrum. It is possible that the gas temperature in the inlet/reactor was insufficient to denature the protein on the millisecond time scale. Alternatively, it is also possible that in our studies the protein ions desorb from the microdroplet in the inlet/reactor before the droplet can attain a high enough solution temperature to denature the protein and affect its ultimate charge state. However, even though the protein might not denature in the microdroplet solution, it could still alter its three-dimensional structure subsequent to desorption or desolvation while still entrained in the heated gas flow. As noted earlier, gas-phase denaturation would not necessarily display the characteristic shift in charge-state distribution accompanying many solution-phase denaturations. In our capillary inlet studies, charge-state distributions were, under some conditions, sensitive to capillary temperature for ubiquitin in water electrosprayed with a coaxial water sheath. That observation was surprising and is not entirely understood. The observed charge-state distribution appeared to be very sensitive to solution composition or the condition of the fused silica capillary. At times when the charge distributions were observed to be sensitive to temperature, contributions from the highest charge states changed dramatically as the 0.1 $\mathrm{cm}$ i.d. capillary inlet/reactor temperature ranged from $40{ }^{\circ} \mathrm{C}$ to $170^{\circ} \mathrm{C}$. Consequently, these temperature results caused concern over the validity of proton transfer experiments carried out at inlet/reactor temperatures of $150{ }^{\circ} \mathrm{C}$ (as in Figures 6 and 7). Proton transfer experiments with DMA were repeated at capillary wall temperatures of $100^{\circ} \mathrm{C}$. Although the studies demonstrated that denaturation might be possible during ESI even at $100{ }^{\circ} \mathrm{C}$, lower temperature experiments were not possible because of the reduced sensitivity arising from clustering of the protein with DMA. (Clustering can occur both in the inlet/reactor and downstream in the supersonic gas expansion. Our ability to decluster by elevating the capillary-skimmer bias was limited by discharge at biases exceeding $500 \mathrm{~V}$.) However, no significant difference in reactivity with equal amounts of DMA was observed for ubiquitin electrosprayed from a water solution with a water sheath versus ubiquitin sprayed from $5 \%$ acetic acid $/ 47.5 \%$ acetonitrile $/ 47.5 \% \mathrm{H}_{2} \mathrm{O}$ with an acetonitrile sheath, or from a 5\% acetic acid/water solution with a water sheath under these $100{ }^{\circ} \mathrm{C}$ conditions. It was interesting to note, however, that the reactivity of ubiquitin electrosprayed from any of these solutions increased with decreasing temperature for reactions with DMA as well as for reactions with DEA and TMA. This interesting observation might indicate the presence and shape of an energy barrier to proton transfer. Formation of a protein-amine complex may be a precursor to proton transfer, so that lower temperatures facilitate formation of the complex and proton transfer. Alternatively, these results can be interpreted as suggesting transition to a less compact structure as temperature is increased.

Another question that arises is whether collisional declustering at elevated capillary-skimmer biases alters the results obtained at lower voltages under clustering conditions, that is, is the charge state of maximum intensity (integrated over all amine adducts for that charge state) the same at different capillary-skimmer biases for a given amount of reagent? (It could be imagined that the extra energy imparted by interface collisions drives reactions to yield lower charge-state products.) However, under the conditions employed in these studies there was no evidence that the charge state of maximum intensity changed with capillaryskimmer bias. 


\section{Reactions with Cytochrome $\mathrm{c}$}

Proton transfer reactions of bovine cytochrome $c\left(\mathrm{M}_{\mathrm{r}}\right.$ 12,231) with DMA, TMA, and $\mathrm{NH}_{3}$ were explored under similar conditions. Solution conditions examined included cytochrome $c$ dissolved in water with a water sheath, and cytochrome $c$ in 5\% acetic acid/ water and electrosprayed with either a methanol or water sheath. Figures $8 \mathrm{a}$ and $9 \mathrm{a}$ show mass spectra for the protein obtained from the two different solutions. Spectra obtained under the same conditions but with $5 \times 10^{-5} \mathrm{~g} / \mathrm{sec}$ DMA are illustrated in Figures $8 \mathrm{~b}$ and $9 \mathrm{~b}$. Clearly, the product spectra from the DMA reactions differ from one another, but are the differences significant? Do they arise from rate differences for equally charged ions or do they reflect the widely differing initial charge-state distributions of Figures 8a and $9 \mathrm{a}$ ? Figures $8 \mathrm{c}$ and $9 \mathrm{c}$ shuw the mass spectra after addition of a much higher DMA flow $\left(8 \times 10^{-4} \mathrm{~g} / \mathrm{sec}\right)$. Attachment of multiple DMA molecules to the protein is apparent for both solutions from the broadening of the peaks. Again, we find that the product spectra from reaction with ions from ESI of the two solution conformations differ, but that the differences are quite small. We cannot exclude the possibility that the small differences arise from the wide differences in initial charge distributions, rather than any difference in reaction rate. For DMA additions ranging from $2 \times$ $10^{-5} \mathrm{~g} / \mathrm{sec}$ to $1 \times 10^{-3} \mathrm{~g} / \mathrm{sec}$, as well as for reactions with $\mathrm{DEA}, \mathrm{NH}_{3}$, and IMA over similar flow ranges, the difference in maximum charge state observed differed by, at most, one charge state for the different

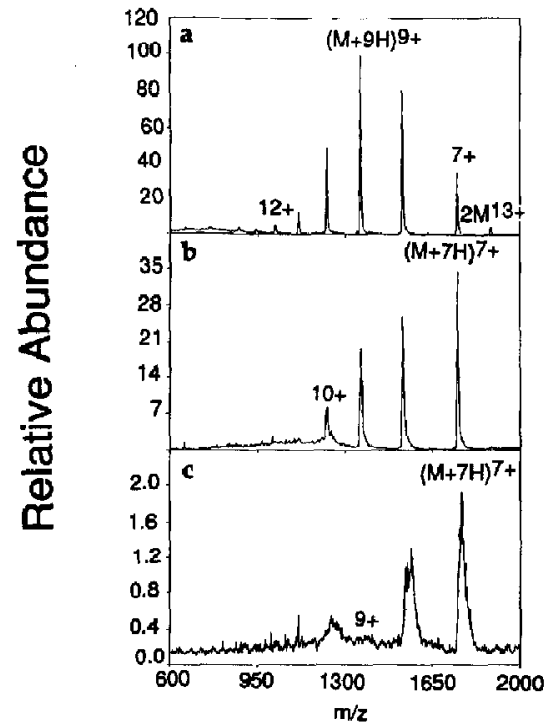

Figure 8. (a) ESI mass spectrum of bovine cytochrome $c\left(\mathrm{M}_{\mathrm{r}}\right.$ 12,231) electrosprayed from a water solution and water sheath (capillary-skimmer bias: $+250 \mathrm{~V}$; capillary temperature: $150^{\circ} \mathrm{C}$ ). (b) As above, but with addition of $5 \times 10^{-5} \mathrm{~g} / \mathrm{sec}$ DMA. (c) As above, but with addition of $8 \times 10^{-4} \mathrm{~g} / \mathrm{sec}$ DMA.

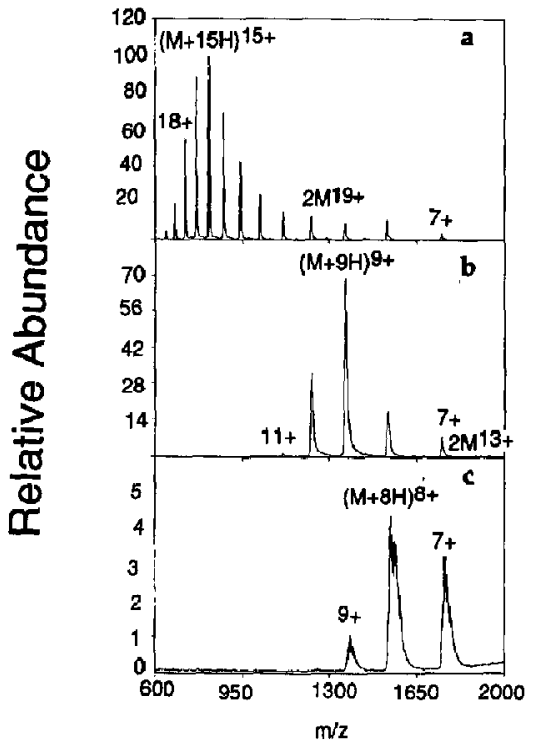

Figure 9. (a) ESI mass spectrum of bovine cytochrome $c$ electrosprayed from a 5\% acetic acid/water solution and methanol sheath (capillary-skimmer bias: $+250 \mathrm{~V}$; capillary temperature: $150^{\circ} \mathrm{C}$ ). (b) As above, but with addition of $5 \times 10^{-5} \mathrm{~g} / \mathrm{sec}$ DMA. (c) As above, but with addition of $8 \times 10^{-4} \mathrm{~g} / \mathrm{sec}$ DMA.

solution conditions studied. Clearly, if there are reaction rate differences under these conditions arising from structural effects, they are quite subtle. It would be desirable to follow these reactions over a higher $m / z$ range [16] so that the reactions can be driven to lower charge states. Subtle reaction rate differences might be expected to be more apparent at lower charge because contributions from the differences in initial charge-state distributions will be less important. On the other hand, recent results obtained with an extended $m / z$ range instrument [16] suggest that at very low charge states reactivity depends more strongly on the intrinsic reactivity of a particular charge site rather than upon Coulombic contributions (due to the more widely spaced charge sites). This suggests the potential dilemma that too extensive charge shifting may lead to a situation where reactivity becomes independent of higher order structure.

Cytochrome $c$ solutions were also electrosprayed at lower capillary temperatures (down to $70^{\circ} \mathrm{C}$ ) to look for evidence of thermal denaturation. Thermal denaturation of cytochrome $c$ in solution has been explored by using ESI by Le Blanc et al. [26] and Mirza et al. [22]. We observed no change in the ESI-MS charge-state distributions with changes in capillary temperature for cytochrome $c$ electrosprayed from $5 \%$ glacial acetic acid $/ \mathrm{H}_{2} \mathrm{O}$ with a methanol sheath flow. This was not unexpected because the protein is rapidly denatured at room temperature under these solution conditions. As illustrated in Figure 10, however, changes were noted for an aqueous solution of the protein in water (electrosprayed with a water sheath) over the capillary 


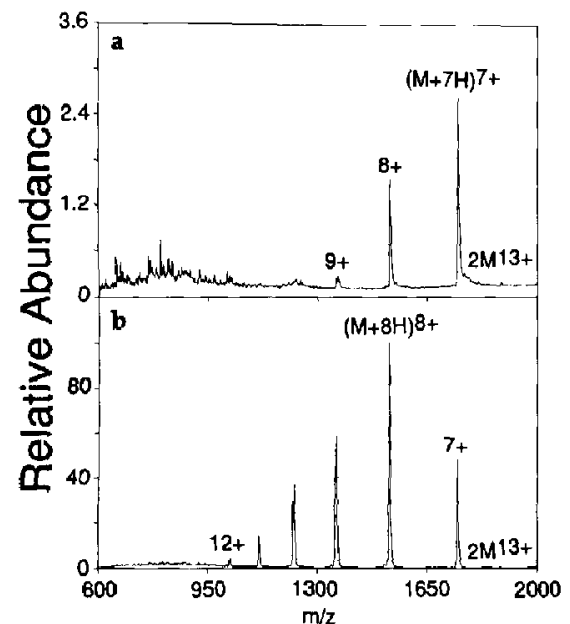

Figure 10. (a) ESI mass spectrum of bovine cytochrome $c$ electrosprayed from a water solution with a water sheath (capillaryskimmer bias: $+450 \mathrm{~V}$; capillary temperature: $70{ }^{\circ} \mathrm{C}$. (b) As above, but with the capillary inlet at $150^{\circ} \mathrm{C}$.

temperature range of $70{ }^{\circ} \mathrm{C}$ to $260^{\circ} \mathrm{C}$. These results provide direct evidence that the protein may be denatured while solvated in the electrosprayed droplets or in a solvated form before the maximum charge state is determined. While the exact solution conditions are uncertain during the actual ion formation process, the denaturation must be sufficiently fast to occur on the millisecond time scale of transmission through the interface. Importantly, the results also indicate that denaturation may occur in the inlet capillary, at least for cytochrome $c$, in the temperature range relevant to the present studies. Conversely, the results also suggest that higher order structure might be preserved for sufficiently gentle interface conditions.

Proton transfer reactions with DMA $\left(2 \times 10^{-5} \mathrm{~g} / \mathrm{sec}\right.$ to $3 \times 10^{-4} \mathrm{~g} / \mathrm{sec}$ ) were also examined at the relatively low capillary inlet temperature of $100{ }^{\circ} \mathrm{C}$ to minimize denaturation in the interface. Once again, however, only small differences were observed for reactions of ions generated from ESI of different solution conformations at equivalent amine flow rates. The differences in maximum charge state observed were always within one charge state. Surprisingly, and in contrast to ubiquitin, as the capillary temperature was increased, the proton transfer reactivity of DMA with cytochrome $c$ always increased. That is, as capillary temperature increased for a given DMA flow rate, the average cytochrome $c$ charge state detected by the mass spectrometer decreased.

Clustering with multiple amine molecules was more pronounced with the higher proton affinity TMA than with an equal amount of DMA under the same capillary inlet conditions. In some cases, for example, with small amine flows, more clustering was observed for higher charge states than for lower charge states, as illustrated in Figure 11. This observation is consistent

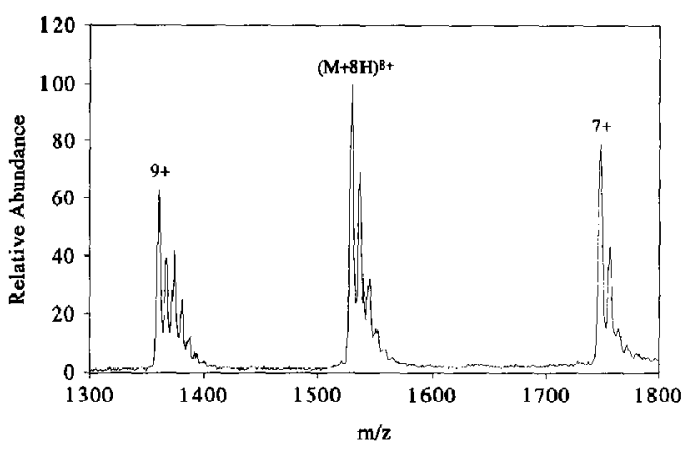

Figure 11. ESI mass spectrum of bovine cytochrome $c$ in $5 \%$ acetic acid/water with a water sheath and addition of $6 \times$ $10^{-5} \mathrm{~g} / \mathrm{sec}$ TMA. The capillary inlet temperature was $70^{\circ} \mathrm{C}$ and the capillary-skimmer bias was $400 \mathrm{~V}$. Note the enhanced clustering of the higher charge states.

with a clustering process occurring in the inlet, prior to the supersonic expansion, reflecting a competition between proton transfer and cluster formation that depends upon charge state. Similar observations have been made previously for proton transfer reactions using an ITMS [34]. At higher amine flows and higher nozzle voltages, larger numbers of amine adducts were observed for lower charge-state protein ions, reflecting (1) the larger contribution from condensation in the supersonic expansion at higher amine flows and (2) that the higher charge states are more effectively collisionally activated in the interface, detaching more of the amine adducts. As noted previously [34] the $\mathrm{m} / \mathrm{z}$ spacing of the amine-protein cluster ions is useful in identifying the charge states of parent ions, product ions, and impurities.

Reactions were also carried out with $\mathrm{NH}_{3}$ to probe behavior with lower proton affinity reagents. A consideration in the $\mathrm{NH}_{3}$ experiments was to examine reaction rates of the highest charge-state molecules generated from different solution conformers. For example, would the $(M+11 H)^{11+}$ ions generated by ESI of a solution containing a "folded conformation" react at a rate similar to the $(\mathrm{M}+20 \mathrm{H})^{20+}$ ions generated by ESI of a solution containing the denatured protein? These experiments test the following premise: if there are no reactivity differences for equally charged ions electrosprayed from different solution conformers, and we add a flow of reagent sufficient to react with only the highest charge states of ions sprayed from a denatured solution, then that same flow of reagent applied to the lower charge-state ions generated from ESI of a folded conformation should show essentially no reaction. Should significant reaction be observed for ions electrosprayed from the folded conformation, despite their low charge states, differences in gas-phase structure would be indicated. Probing reactions with lower proton affinity reagents in this manner can be more sensitive to reaction rate differences, because this approach does not require that we weigh the contribution of the initial charge-state distributions on the 
product charge-state distributions. However, in these experiments we observed very little reaction of the ions generated by electrospray of the "folded" conformation, suggesting similar reactivities for ions produced from these two solutions. Again, we fail to find clear evidence of structural differences in the gas phase.

\section{Reactions with Myoglobin}

The influence of the solution-phase conformation of myoglobin on ESI mass spectra has been investigated by Katta and Chait [21] and by several other groups $[10,20,26,55]$. Horse heart myoglobin solutions in $\mathrm{H}_{2} \mathrm{O}\left(\mathrm{H}_{2} \mathrm{O}\right.$ sheath liquid) and in $5 \%$ acetic acid/ $\mathrm{H}_{2} \mathrm{O}$ (methanol sheath liquid) were electrosprayed and yielded the mass spectra shown in Figures 12a and $13 \mathrm{a}$, respectively. The $5 \%$ acetic acid $/ \mathrm{H}_{2} \mathrm{O}$ solution yielded the apo-protein $\left(M_{\mathrm{r}} 16,951.5\right)$ [56], with a very small contribution from apo-protein dimers (Figure 13a), while the $\mathrm{H}_{2} \mathrm{O}$ solution yielded primarily the intact heme-attached protein $\left(\mathrm{M}_{\mathrm{r}} 17,568.0\right.$, Figure 12a). Nearly all of the apomyoglobin in the $9+-14+$ charge states of Figure 12a (labeled by "*") arises from collisional activation in the ESI-MS interface at the elevated capillary-skimmer bias and $150^{\circ} \mathrm{C}$ capillary temperature employed. (These conditions were selected to reduce the number of amine adducts clustering to the proteins in Figures $12 \mathrm{~b}, \mathrm{c}$ and $13 \mathrm{~b}, \mathrm{c}$.) At lower capillary-skimmer biases it was possible to obtain good spectra of the holo-protein with almost no contribution from apomyoglobin. Figures $12 b$ and $13 b$ illustrate the ESI mass spectra resulting from addition of $2 \times$

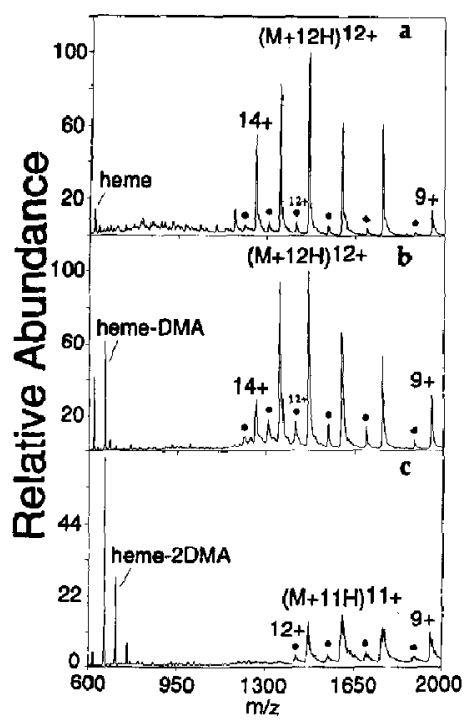

Figure 12. (a) ESI mass spectrum of horse heart myoglobin electrosprayed in water with a water sheath (capillary-skimmer bias: $+350 \mathrm{~V}$; capillary temperature: $150^{\circ} \mathrm{C}$ ). (b) As above, but with addition of $2 \times 10^{-5} \mathrm{~g} / \mathrm{sec}$ DMA. (c) As above, but with addition of $3 \times 10^{-4} \mathrm{~g} / \mathrm{sec}$ DMA.

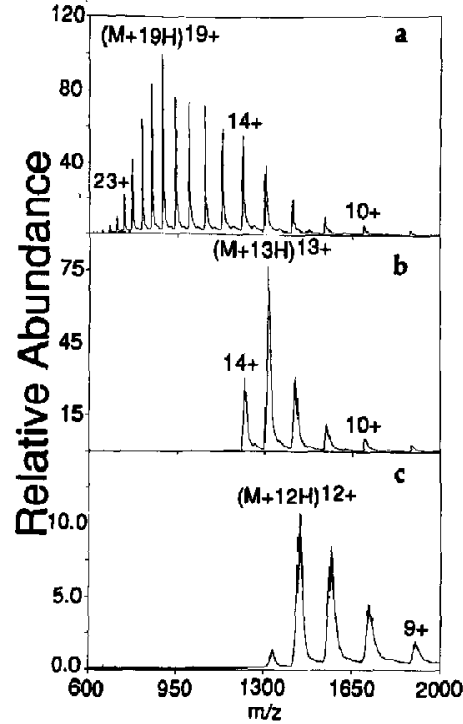

Figure 13. (a) ESI mass spectrum of horse heart myoglobin electrosprayed in $5 \%$ acetic acid/water with a methanol sheath (capillary-skimmer bias: $+350 \mathrm{~V}$; capillary temperaturc: $150{ }^{\circ} \mathrm{C}$ ). (b) As above, but with addition of $2 \times 10^{-5} \mathrm{~g} / \mathrm{sec}$ DMA. (c) As above, but with addition of $3 \times 10^{-4} \mathrm{~g} / \mathrm{sec}$ DMA.

$10^{-5} \mathrm{~g} / \mathrm{sec}$ DMA, while Figures $12 \mathrm{c}$ and $13 \mathrm{c}$ show the effect of adding $3 \times 10^{-4} \mathrm{~g} / \mathrm{sec}$ of the amine. Addition of amine reagent elevated the ratio of apomyoglobin to holomyoglobin only slightly (Figure 12), which suggests that the charge-shifted apo-protein arises primarily from collisional dissociation of the charge-shifted holo-protein in the inlet, although heme loss associated with the charge-shifting reaction cannot be ruled out as a lower yield contributor. It is interesting that for all DMA additions ranging from 0 to $8 \times 10^{-4} \mathrm{~g} / \mathrm{sec}$, as well as for reactions with TMA over similar flow ranges, the changes in the maximum charge state observed differed by, at most, one charge state for the two different solution conditions studied. However, the actual distribution is significantly shifted to lower charge states for the spectra shown in Figure $12 b$ and $c$, suggesting structural differences for at least some portion of the ion population. The reaction rate differences are small enough for this protein that their presence must be viewed as providing only tentative evidence for gas-phase conformation differences.

In some experiments, amines appeared to cluster more readily to multiply charged ions from myoglobin electrosprayed from acetic acid/water solutions with a methanol sheath than to multiply charged ions electrosprayed from water solutions with a water sheath. One might also ascribe these differences to differences in gas-phase conformation, but this behavior was not observed in all experiments, and we cannot rule out other explanations for these observations, such as differing degrees of ion solvation depending on the elec- 
trospray conditions. Clearly, this observation warrants further study.

It is also apparent from Figure 12 that heme reacts with DMA to form (heme $\cdot \mathrm{DMA}+\mathrm{H})^{+}$and (heme. 2DMA $+\mathrm{H}^{+}{ }^{+}$. Similarly, (heme $\left.\cdot \mathrm{TM} \Lambda+\mathrm{H}\right)^{+}$, (heme $\cdot 2 \mathrm{TMA}+\mathrm{H})^{+}$, and (heme $\left.\cdot 3 \mathrm{TMA}+\mathrm{H}\right)^{+}$were observed when TMA reactions were investigated. More study is needed to establish whether the observed heme-amine adducts arise from reaction of amines with free heme ${ }^{+\cdot}$ or (heme $\left.+\mathrm{H}\right)^{+}$, whether they are a reaction product of the heme-protein, or a combination of the two pathways.

Sometimes additional peaks corresponding to a second charge-state distribution were observed in the ESI mass spectra of myoglobin in water with a water sheath in the $m / z 650-1200$ region, as shown in Figures 12a and 14a. The observation of this second distribution appears to depend on the solution or fused silica capillary conditions. The second charge distribution, labeled by " $"$ " in Figure 14, yields peaks for apomyoglobin and additional adduct peaks associated with each charge state at approximately $(\mathrm{M}+272+$ $\mathrm{nH})^{\mathrm{n}+},(\mathrm{M}+561+\mathrm{nH})^{\mathrm{n}+}$, and $(\mathrm{M}+883+\mathrm{nH})^{\mathrm{n}+}$. This example is unusual in that the second, higher charge-state distribution frequently has more adducts associated with it than the dominant, lower chargestate distribution. This is in contrast to the typical observation that lower charge states carry more counterion adducts because they experience lower energy collisions in the interface. The observation could sug-

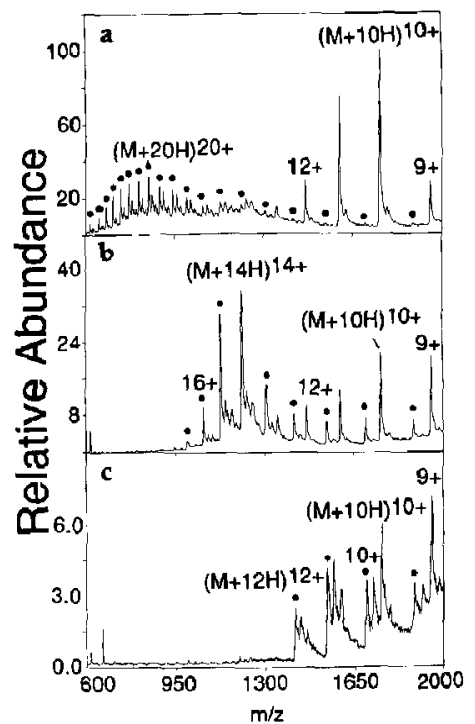

Figure 14. (a) ESI mass spectrum of horse heart myoglobin electrosprayed in water with a water sheath liquid under conditions yielding a second, higher charge-state distribution, labeled by "." (capillary-skimmer bias: $+350 \mathrm{~V}$; capillary temperature: $150^{\circ} \mathrm{C}$ ). (b) As above, but with addition of less than $2 \times 10^{-5} \mathrm{~g} / \mathrm{sec}$ DMA. (c) As above, but with addition of approximately $1 \times 10^{-3} \mathrm{~g} / \mathrm{sec}$ DMA. gest that the high charge-state distribution arises from a different solution conformation. This second chargestate distribution provided an opportunity to simultaneously compare the reactivities of the highest charge states of both distributions. Moreover, the additional adducts associated with the higher charge-state distribution made it possible to follow the reactions of those species even wher the product charge states overlapped with the other charge-state distribution (see Figure 14). These studies indicated that the proton transfer reactivity depended primarily upon the number of charges, and did not show a discontinuity in rate for equally charged ions arising from the different starting distributions. Addition of small amounts of DMA or TMA shifted only the charge states of the high charge-state distribution. As more reagent was added, the high charge-state distribution shifted farther until it overlapped the dominant, low charge-state distribution, and with still more reagent, the adduct peaks shifted along with peaks for the highest charge states of the dominant distribution. The implications of this observation are striking: either reactivity differences are small or no significant structural differences persist in the gas phase.

Possible effects of thermal denaturation in the capillary interface were considered for myoglobin as they were for the proteins discussed earlier. The ESI mass spectrum obtained by electrospraying myoglobin in $5 \%$ acetic acid/water with a methanol sheath did not vary as a function of temperature, other than in overall intensity. Similarly, the mass spectrum for myoglobin electrosprayed from a water solution (with a water sheath) only changed in intensity as a function of temperature and in the ease at which the heme subunit was collisionally detached. Reactions of DMA with myoglobin electrosprayed from water (with a water sheath) and myoglobin electrosprayed from $5 \%$ acetic acid/water (with a methanol sheath) were compared at $100{ }^{\circ} \mathrm{C}$. Only small differences were observed for reactions of ions generated from different solution conformations with equal flows of amine, similar to those observed at the higher temperature. The proton transfer reactivity of myoglobin with DMA and TMA did not vary dramatically with temperature, in contrast to the ubiquitin and cytochrome $c$ results discussed earlier.

\section{Conclusions}

These studies have applied proton transfer reactions to nontrapping mass spectrometers using our novel capillary inlet/reactor approach. We have particularly stressed careful control of solution conditions herause most biochemical examinations of conformation are performed with well-characterized solution conditions. Moreover, we have attended to inlet conditions as much as possible because of our belief (now supported by direct evidence) that gas-phase and/ or microdroplet solution-phase conformation might 
be perturbed by higher inlet temperatures. The present results suggest that thermal denaturation effects observed in the capillary interface are worthy of consideration in future conformation studies and may also be of note for some noncovalent interaction work. The present results also serve to highlight the complexity of the processes contributing to determining the charge-state distribution observed in ESI-MS.

Based on these studies, we find only tentative evidence suggesting that higher order structure in nondisulfide linked proteins are preserved in the gas phase. Indeed, in most cases the results are more suggestive of the absence of significant structural differences. The absence of more definitive differences in most cases raises the question as to whether the proton transfer reactions employed are a sensitive probe of higher order structural differences. As mentioned earlier, however, it is not clear that proton transfer is the best method for probing gas-phase higher order structure, or even that multiple collisions with amine reagent do not perturb any surviving higher order structure. It is interesting that an inlet/reactor H/D exchange study [39] also failed to see the differences in reactivity demonstrated in the FTMS work [20], suggesting that further comparisons of both high and low pressure reactions may be of interest. For example, it has been argued that $\mathrm{H} / \mathrm{D}$-isotope exchange in gaseous ion-molecule reactions occurs as a multistep reaction involving proton transfers and rearrangements in long-lived activated ion-molecule complexes [57-59]. The shorter time scale and multiple collisions involved in the inlet/reactor experiments could alter the competition between various reaction pathways, yielding results that differ from those of the FTMS experiments. The strikingly similar reactivities observed in this work for apomyoglobin and heme-intact myoglobin suggest that the structures for these species may be similar in the gas phase for our interface conditions. We have earlier speculated on the role of Coulombic forces in causing structural differences to be manifested as different charge-state distributions. It is also possible that due to our need to shift the charge-state distribution to a large extent, we reduce the role of Coulombic contributions to a level that is insignificant in defining the effective proton affinities of charge sites. Clearly, comparisons of high and low pressure reactions and with species of lower proton affinity will be of further interest. Finally, the present study provides the first direct evidence of denaturation during the electrospray process and prior to the point at which charge state is determined. Such processes may be a significant factor in our failure to observe greater differences in reactivity, possibly even at lower temperatures.

\section{Acknowledgments}

We thank the Director, Office of Health and Environmental Research, U.S. Department of Energy and Internal Exploratory Research of the Molecular Science Research Center for support of this research through Contract DE-AC06-76RLO 1830. Pacific
Northwest Laboratory is operated by Battelle Memorial Institute for the U.S. Department of Energy.

\section{References}

1. (a) Dole, M.; Mack, L. L.; Hines, R. L.; Mobley, R. C.; Ferguson, L. D.; Alice, M. B. J. Chem. Phys. 1968, 49, 2240-2249; (b) Mack, L. L.; Kralik, P.; Rheude, A.; Dole, M. J. Chem. Phys. 1970, 52, 4977-4986; (c) Clegg, G. A.; Dole, M. Biopolymers 1971, 10, 821-826; (d) Teer, D.; Dole, M. J. Polym. Sci. 1975, 13, 985-995; (e) Gieniec, J.; Mack, L. L.; Nakamae, K.; Gupta, C.; Kumar, V.; Dole, M. Biomed. Mass Spectrom. 1984, 17. 259-268.

2. (a) Yamashita, M; Fenn, J. B. J. Phys. Chem. 1984, 88, 4451-4459; (b) Yamashita, M.; Fenn, J. B. J. Phys. Chem. 1984, 88, 4671-4675; (c) Whitehouse, C. M.; Dreyer, R. N.; Yamashita, M.; Fenn, J. B. Anal. Chem. 1985, 57, 675-679; (d) Wong, S. F.; Meng, C. K.; Fenn, J. B. J. Phys. Chem. 1988, 92, 546-550; (e) Meng, C. K.; Mann, M.; Fenn, J. B. Z. Phys. D 1988, 10, 361-368.

3. (a) Fenn, J. B.; Mann, M.; Meng, C. K.; Wong, S. F; Whitehouse, C. M. Science 1989, 246, 64-71; (b) Fenn, J. B.; Mann, M.; Meng, C. K.; Wong, S. F, Whitehouse, C. M. Mass Spectrom. Rev. 1990, 9, 37-70; (c) Mann, M. Org. Mass. Spectrom. 1990, 25, 575-587.

4. (a) Aleksandrov, M. L.; Gall, L. N.; Krasnov, V. N.; Nikolaev, V. I.; Pavlenko, V. A.; Shkurov, V. A. Dokl. Akad. Nauk. USSR 1984, 277, 379-383; (b) Aleksandrov, M. L.; Gall, L. N.; Krasnov, V. N.; Nikolaev, V. I.; Pavlenko, V. A.; Shkurov, V. A.; Baram, G. I; Gracher, M. A.; Knorre, V. D.; Kusner, Y. S. Bioorg, Kim. 1984, 10, 710-712; (c) Aleksandrov, M. L.; Besuklandnikov, P. V.; Grachev, M. A.; Elyakova, L. A.; Zyyaginsteva, T. N.; Kondratsev, V. M.; Kusner, Y. S.; Mirgorodskaya, O. A.; Fridlyansky, G. V. Bioorg. Kim. 1986, 12, 1689-1692; (d) Aleksandrov, M. L.; Baram, G. I.; Gall, L. N.; Krasnov, N. V.; Kusner, Y. S.; Mirgorodskaya, O. A.; Nikolaev, V. I.; Shkurov, V. A. Bioorg. Kim. 1985, 11, 700-705; (e) Aleksandrov, M. L.; Baram, G. I.; Gall, L. M.; Grachev, M. A.; Knorre, V. D.; Krasnov, N. V.; Kusner, Y. S.; Mirgorodskaya, O. A.; Nikolaev, V. I.; Shkurov, V. A. Bioorg. Kim. 1985, 11, 705-708; (f) Aleksandrov, M. L.; Kondratsev, V. M.; Kusner, Y. S.; Mirgorodskaya, O. A.; Podtelezhrikov, A. V.; Fridlyansku, G. V. Bioorg. Kim. 1988, 14, 852-857.

5. Smith, R. D.; Loo, J. A.; Ogorzalek Loo, R. R.; Busman, M.; Udseth, H. R. Mass Spectrom. Rev. 1991, 10, 359-451.

6. Ganem, B.; Li, Y.; Henion, J. D. 1. Am. Chem. Soc. 1991, 113, 6294-6296.

7. Ganem, B.; Li, Y.; Henion, J. D. J. Am. Chem. Soc. 1991, 113, 7818-7819.

8. Lumb, K. J.; Aplin, R. T.; Radford, S. E.; Archer, D. B.; Jeenes, D. J.; Lambert, N.; MacKenzie, D. A.; Dobson, C. M.; Lowe, G. FEBS 1992, 296, 153-157.

9. Baca, M.; Kent, S. B. H. J. Am. Chem. Soc. 1992, 114, 3992-3993.

10. Loo, J. A.; Ogorzalek Loo, R. R.; Goodlett, D. R.; Smith, R. D.; Fuciarelli, A. F.; Springer, D. L.; Thrall, B. D.; Edmonds, C. G. In Techniques in Protein Chemistry IV; Angeletti, R. H., Ed. Academic Press: San Diego, 1993.

11. Ogorzalek Loo, R. R.; Goodlett, D. R.; Smith, R. D.; Loo, J. A. I. Am. Chem. Soc. 1993, 115, 4391-4392.

12. Smith, R. D.; Light-Wahl, K. J.; Winger, B. E.; Lao, J. A. Org. Mass Spectrom. 1992, 27, 811-821.

13. Goodlett, D. R.; Camp II, D. G.; Hardin, C. C.; Corregan, M.; Smith, R. D. Biol. Environ. Mass Spectrom. 1993, 22, 81.

14. Light-Wahl, K. J.; Springer, D. L.; Winger, B. E.; Edmonds, C. G.; Camp II, D. G.; Thrall, B. D.; Smith, R. D. J. Am. Chem. Soc. 1993, 115, 803-804; Ganem, B.; Li, Y.-T.; Henion, J. T. Tetra Lett. 1993, 34, 1445-1448. 
15. Meng, C. K.; Fenn, J. B. Org. Mass Spectrom. 1991, 26, 542-549.

16. Winger, B. E.; Light-Wahl, K. J.; Ogorzalek Loo, R. R.; Udseth, H. R.; Smith, R. D. J. Am. Soc. Mass Spectrom. 1993, 1, 536-545

17. Ganguly, A. K.; Pramanik, B. N.; Tsarbopoulos, A.; Covey, T. R.; Huang, E.; Fuhrman, S. A. J. Am. Chem. Soc. 1992, 114, 6559-6560.

18. Ogorzalek Loo, R. R.; Loo, J. A.; Udseth, H. R.; Fulton, J. L.; Smith, R. D. Rapid Commun. Mass Spectrom. 1992, 6, 159-165.

19. Winger, B. E.; Light-Wahl, K. J.; Rockwood, A. L.; Smith, R. D. J. Am. Chem. Soc. 1992, 114, 5897-5898.

20. Suckau, D.; Shi, Y.; Beu, S. C.; Senko, M. W.; Quinn, J. P.; Wampler III, F. M.; McLafferty, F. W. Proc. Natl. Acad. Sci. USA 1993, 90, 790-793.

21. Katta, V; Chait, B. T. J. Am. Chem. Soc. 1991, 113, 8534-8535.

22. Mirza, U. A.; Cohen, S. L.; Chait, B. T. Anal. Chem. 1993, 65, $1-6$.

23. Katta, V; Chait, B. T. Rapid Commun. Mass. Spectrom. 1991, 5 , 214; Katta, V.; Chait, B. T. I. Am. Chem. Soc. 1993, 113, 6317-6321.

24. Loo, J. A.; Ogorzalek Loo, R. R.; Udseth, H. R.; Edmonds, C. G.; Smith, R. D. Rapid Commun. Mass Spectrom. 1991, 5, 101.

25. Chowdhury, S. K.; Katta, V.; Chait, B. T. I. Am. Chem. Soc. $1990,112,9012$.

26. Le Blanc, J. C. Y.; Beuchemin, D.; Siu, K. W. M.; Guevremont, R.; Berman, S. S. Org. Mass Spectrom. 1991, 26, 831.

27. Brown, C.; Camilleri, P.; Haskins, N. J.; Saunders, M. J. Chem. Soc, Chem. Conmun. 1992, 761-764.

28. Loo, J. A.; Edmonds. C. G.; Smith, R. D. Science 1990, 248, 201.

29. Loo, J. A.; Edmonds, C. G.; Smith, R. D. Amal. Chem. 1991, 63. 2488.

30. Loo, J. A.; Edmonds, C. G.; Ugorzalek Loo, K. K.; Udseth, H. R; Smith, R. D. In Experimental Mass Spectrometry; Russell, D. H., Ed. Plenum Press, New York, 1994, pp 243-285.

31. (a) Feng, R.; Konishi, Y. Proceedings of the 39th Anntual ASMS Conference on Mass Spectrometry and Allied Topics; Nashville, TN, 1991; pp 1432-1433; (b) Covey, T. R.; Douglas, D. J. J. Am. Soc. Mass Spectrom. 1993, 4, 616-623.

32. Mcluckey, S. A.; Van Berkel, G. J.; Glish, G. L. Proceedings of the 38th Annual ASMS Conference on Mass Spectrometry and Allied Topics; Tucson, AZ 1991; pp 1134-1135.

33. McLuckey, S. A.; Van Berkel, G. J.; Glish, G. L. J. Am. Chem. Soc. $1990,112,5668-5670$.

34. McLuckey, S. A.; Glish, G. L.; Van Berkel, G. J. Anal. Chem. 1991, 63, 1971-1978.

35. (a) McLuckey, S. A.; Glish, G. L.; Van Berkel, G. J. Proceedings of the 39th Annual ASMS Conference on Mass Spectrometry and Allied Topics; Nashville, TN, 1991, pp 901-902; (b) Ikonomou, M. G; Kebarle, P. Int. J. Mass Spectrom. Ion Proc. 1992, 117,
283-298.

36. Winger, B. E.; Light-Wahl, K. J; Smith, R. D. J. Am. Soc. Mass Spectrom. 1992, 3, 621-630.

37. Feng, R; Konishi, Y. Proceedings of the 40th Annual ASMS Conference on Mass Spectrometry and Allied Topics; Washington, DC, 1992; pp 1635-1636.

38. Ogorzalek Loo, R. R,; Loo, J. A.; Smith, R. D. Proceedings of the 40th Annual ASMS Conference on Mass Spectrometry and Allied Topics; Washington, DC, 1992; pp 645-646.

39. Winger, B. E.; Light-Wahl, K. J.; Smith, R. D. Proceedings of the 40th Annwal ASMS Conference on Mass Spectrometry and Allied Topics; Washington, DC, 1992; pp 481-482.

40. Smith, R. D.; Olivares, J. A.; Nguyen, N. T.; Udseth, H. R. Anal. Chem. 1988, 60, 436-441.

41. (a) Smith, R. D.; Barinaga, C. J.; Udseth, H. R. Anal. Chem. 1988, 60, 1948-1952; (b) Loo, J. A.; Udseth, H. R.; Smith, R. D. Biomed. Environm. Mass Spectrom. 1988, 17, 411-414.

42. Ogorzalek Loo, R. R.; Udseth, H. R.; Smith, R. D. J. Phys. Chem. 1991, 95, 6412-6415.

43. Ogorzalek Loo, R. R,; Udseth, H. R,; Smith, R. D. J. Am. Soc. Mass Spectrom. 1992, 3, 695-705.

44. Rockwood, A. L; Busman, M.; Udseth, H. R.; Smith, R. D. Rapid Commun. Mass Spectrom. 1991, 5, 582-585.

45. Busman, M.; Rockwood, A. L.; Smith, R. D. I. Phys. Chem. 1992, 96, 2397-2400.

46. Aue, D. H.; Bowers, M. T. In Gas Phase lon Chemistry; Bowers, M. T, Ed. Academic Press, New York, 1979.

47. Loo, J. A.; Udseth, H. R.; Smith, R. D. Rapid Commun. Mass Specrom. 1988, 2, 207-210.

48. Barinaga, C. J.; Edmonds, C. G.; Udseth, H. R.; Smith, R. D. Rapid Commun. Mass Spectrom. 1989, 3, 160-164.

49. Ikonomou, M. G, Blades, A. T.; Kebarle, P. J. Am. Soc. Mass. Spectrom. 1991, 2, 497-505.

5u. Cleland, W. W. Biachemistry 1964, 3,480.

51. Loo, J. A.; Edmonds, C. G.; Udseth, H. R,; Smith, R. D. Anal. Chem. 1990, 62, 693.

52. Smith, R. D.; Loo, J. A.; Edmonds, C. G.; Barinaga, C. J.; Udseth, H. R. Anal Chem. 1990, 62, 882.

53. Wilkinson, K. D.; Audhya, T. K. J. Biol. Chem. 1981, 256 , 9235-9241.

54. Rockwood, A. L.; Busman, M.; Smith, R. D. Int. J. Mass Spectrom. Ion Proc. 1991, 111, 103-129.

55. Loo, J. A.; Giordani, A. B.; Muenster, H. Rapid Commun. Mass Spectrom, 1993, 7, 186-189.

56. Zaia, J.; Annan, R. S.; Biemann, K. Rapid Commun. Mass Spectrom. 1992, 6, 32-36.

57. Lias, S. G. J. Phys. Chem. 1984, 88, 4401-4407.

58. Squires, R. R.; Bierbaum, V. M.; Grabowski, J. J.; DePuy, C. H. J. Am. Chem. Soc. 1983, 105, 5185-5192.

59. Ranasinghe, A.; Cooks, R. G.; Sethi, S. K. Org. Mass Spectrom. 1992, 27, $77-88$. 